\section{RSP}

http://www.fsp.usp.br/rsp/
Revista de Saúde Pública

\title{
Factors associated with self-reported discrimination against men who have sex with men in Brazil
}

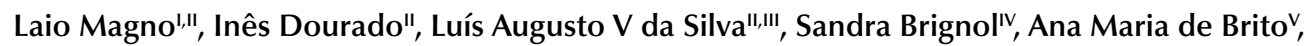
Mark Drew Crosland Guimarães" ${ }^{\mathrm{VI}}$, Adele Benzaken ${ }^{\mathrm{VII}}$, Adriana de A Pinho ${ }^{\mathrm{VIII}}$, Carl Kendall ${ }^{\mathrm{Ix}}$, Ligia Regina Franco Sansigolo Kerr ${ }^{x}$

I Universidade do Estado da Bahia. Departamento de Ciências da Vida. Salvador, BA, Brasil

" Universidade Federal da Bahia. Instituto de Saúde Coletiva. Salvador, BA, Brasil

III Universidade Federal da Bahia. Instituto de Humanidades, Artes \& Ciências Professor Milton Santos. Salvador, BA, Brasil

IV Universidade Federal Fluminense. Instituto de Saúde Coletiva. Niterói, RJ, Brasil

$\checkmark$ Fundação Oswaldo Cruz. Instituto Aggeu Magalhães. Recife, PE, Brasil

vı Universidade Federal de Minas Gerais. Faculdade de Medicina. Departamento de Medicina Preventiva e Social. Belo Horizonte, MG, Brasil

VII Ministério da Saúde. Secretaria de Vigilância em Saúde. Departamento de IST, Aids e Hepatites Virais. Brasília, DF, Brasil

VIII Fundação Oswaldo Cruz. Instituto Oswaldo Cruz. Rio de Janeiro, RJ, Brasil

Ix Center for Global Health Equit. Tulane School of Public Health and Tropical Medicine. New Orleans, Louisiana, USA

x Universidade Federal do Ceará. Departamento de Saúde Comunitária. Fortaleza, CE, Brasil

Correspondence:

Laio Magno

Departamento de Ciências da Vida -

UNEB

Rua Silveira Martins, 2555

Campus I Cabula

41150-000 Salvador, BA, Brasil

E-mail: laiomagnoss@gmail.com

Received: May 10, 2016

Approved: Oct 24, 2016

How to cite: Magno L, Dourado I, Silva LAV, Brignol S, Brito AM, Guimarães MDC, et al. Factors associated with self-reported discrimination against men who have sex with men in Brazil. Rev Saude Publica. 2017;51:102.

Copyright: This is an open-access article distributed under the terms of the Creative Commons Attribution License, which permits unrestricted use, distribution, and reproduction in any medium, provided that the original author and source are credited.

\section{ABSTRACT}

OBJECTIVE: To estimate self-reported discrimination due to sexual orientation among men who have sex with men (MSM) in Brazil and to analyze associated factors.

METHODS: A cross-sectional study of 3,859 MSM recruited in 2008-2009 with respondent driven sampling. Data collection conducted in health centers in 10 Brazilian cities. A face-to-face questionnaire was used and rapid HIV and syphilis tests conducted. Aggregated data were weighted and adjusted odds ratio estimated to measure the association between selected factors and self-reported discrimination due to sexual orientation.

RESULTS: The sample was predominantly young, eight plus years of schooling, pardo (brown), single, low-income, and identified themselves as gay or homosexual. The prevalence of self-reported discrimination due to sexual orientation was $27.7 \%$ (95\%CI 26.2-29.1). Discrimination was independently associated with: age $<30$ years, more years of schooling, community involvement and support, history of sexual and physical violence, suicidal thoughts, and unprotected receptive anal intercourse.

CONCLUSIONS: The prevalence of self-reported discrimination among MSM in Brazil is high. These results challenge the assumptions that MSM-specific prevention and support programs are not required or that health professionals do not need special training to address MSM needs.

DESCRIPTORS: Homosexuality, Male. Sexism. Risk Factors. Socioeconomic Factors. Gender and Health. Health Inequalities. 


\section{INTRODUCTION}

The prevalence of HIV infections among men who have sex with men (MSM) in various countries is disproportionately high ${ }^{1}$. In Brazil, the estimated prevalence of HIV infection between MSM above 18 years of age is around $14.2 \%$ (95\%CI $12.1-16.6)^{2}$.

Among the factors that contribute to the continuation of elevated HIV levels among MSM, social determinants are a stand out, reflecting discrimination and the inequality of social, economic, organizational, and political power for many MSM populations. Combined with a range of risk factors such as sex without condoms, the number of partners, and difficult access to health services and diverse forms of prevention (e.g., Pre-Exposure Prophylaxis and Post-Exposure Prevention), MSM are especially vulnerable in this epidemic ${ }^{4}$. Studies have underlined that stigma and discrimination are among the main contributing factors to the continuation of the epidemic among MSM, often creating barriers to prevention, testing, and treatment services for $\mathrm{HIV}^{5}$.

Another aggravating factor is that homoerotic practices are deemed illegal in 78 countries in the world and, in five countries, are punishable by death ${ }^{6}$. Although homosexuality is not illegal in Latin America and the Caribbean, discrimination is a serious problem? In Brazil, according to the Secretary of Human Rights of the Presidency of the Republic, in 2012, there were around 27 notifications per day of homophobic incidents - and this is assumed to be underreported ${ }^{8}$.

This study revisited the first national HIV surveillance survey among MSM in Brazil to estimate discrimination due to sexual orientation amongst MSM, and to analyze potential associated factors.

\section{METHODS}

This study used data from the national study "Behavior, Attitudes, Practices, and Prevalence of HIV and Syphilis amongst Men who Have Sex with Men", conducted in 10 Brazilian cities (Manaus, Recife, Salvador, Campo Grande, Brasília, Curitiba, Itajaí, Santos, Belo Horizonte, and Rio de Janeiro) between October 2008 and October 2009. Its main objectives were to study the behavior, attitudes, and sexual practices of MSM and estimate the prevalence of HIV and syphilis. The total population was 3,859 men who reported at least one sexual contact with another man in the previous 12 months. Other criteria for inclusion in the study was being 18 years or over, not identifying as transgender, residing in the cities selected in the study, and signing the informed consent form.

In each site the sample was recruited utilizing respondent driven sampling (RDS), ${ }^{9,10}$. This is a chain link sampling method that begins with a convenience sample of members of the target population called "seeds". Initially, formative research was undertaken in each city, which consisted of semi-structured interviews and focus groups. Subsequently, about six MSM (nominated seeds), with relatively large contact networks characterized by a diverse age range and socioeconomic makeup were chosen by the researchers in each city. A total of 140 seeds were used across the sites. Each participant received three coupons to recruit participants to the study. This process was repeated until the sample size was reached $(n=3,859)$. Participants received a primary incentive of $\mathrm{R} \$$ (Brazilian Real 2009) 15.00 (US\$10.00) and an incentive of R\$(Brazilian Real 2009) 10.00 (US\$6.67) for each of their recruits who completed the survey. Data collection took place in the health centers of City Health Departments. A face-to-face questionnaire was used and included questions concerning the size of the social networks of the contacts; sociodemographic characteristics; identity and sexual behavior; use of alcohol and other drugs; mental health; self-reported discrimination (for sexual orientation, race, social condition, or age), self-reported history of violence (verbal, physical, sexual); social integration and 
participation; information on sexuality transmitted diseases (STD), access to condoms; health care and STD symptoms.

After the interview, participants were offered a rapid HIV test, using the following tests: Rapid Check HIV-1\&2 (Center for Infectious Diseases, Universidade Federal do Espírito Santo, Vitória, Brazil) and Bio-Manguinhos HIV-1\&2 (Institute for Immunobiological Technology, Fundação Oswaldo Cruz, Rio de Janeiro, Brazil). All participants received pre-and post-test counseling, educational material, and condoms. Those who tested positive for HIV were referred to specific health centers for HIV care. The research project was approved by the National Ethics Commission of Brazilian Research (CONEP 14494). Complete details of the overall study have been reported previously ${ }^{2}$.

\section{Outcome and Other Study Variables}

The main outcome variable of this study is self-reported discrimination due to sexual orientation and it was defined according to the following question: "In the last 12 months, did you feel discriminated against by some person or institution because of your sexual orientation?" Other variables included in the analysis were: a) sociodemographic: age, self-reported skin color, conjugal situation, sexual orientation; b) economic and educational status: monthly income and years of education; c) history of violence: having been forced to have sex (sexual violence), experience of physical violence, and being verbally threatened or humiliated; d) access to health care and social support: STD counseling in the last 12 months, community involvement and support; e) mental health: feeling sad or depressed (never; at least once) in the last six months, had suicidal thoughts in the last six months; f) risk factors for STD: unprotected receptive anal intercourse with casual and steady male partners in the last six months.

\section{Analysis}

As shown in Table 1, there was no indication of homophily with regard to the outcome of interest (self-perceived discrimination) in any of the 10 cities (ranging from 0.955 to 1.125 , median $=1.04$ ). The rationale for data analysis was to use statistical method in order to take into account the dependence among observations, resulting from the recruitment chains and the unequal probabilities of selection and from the different sizes of networks of each participant. The probability that an individual participates in RDS research depends on the size of their social network ${ }^{9}$. To generate a total for the sample, data from each survey were weighted by the inverse probability of individual selection, proportional to the size of the social network reported by each respondent. The procedure is fully described in Kerr et al. ${ }^{2}$

Participants personal social network size and the resulting weight were measured using the question: "How many MSM were 18 or older had people with whom they were familiar

Table 1. Prevalence of self-perceived discrimination of men who have sex with men in 10 cities. Brazil, 2009.

\begin{tabular}{lccccc}
\hline Cities & Unadjusted (\%) & $\mathbf{9 5} \mathbf{C l}$ & Weighted* $(\%)$ & $\mathbf{9 5} \% \mathbf{C l}$ & Homophily \\
\hline Manaus & 36.4 & $33.1-39.6$ & 29.3 & $26.2-32.4$ & 1.030 \\
Recife & 47.0 & $41.6-52.2$ & 39.3 & $34.1-44.4$ & 1.064 \\
Salvador & 34.1 & $29.3-38.9$ & 26.6 & $22.1-31.0$ & 1.019 \\
Brasília & 41.8 & $36.3-.47 .2$ & 39.3 & $33.8-44.7$ & 0.992 \\
Campo Grande & 32.3 & $27.3-37.2$ & 25.9 & $21.3-30.5$ & 1.125 \\
Belo Horizonte & 40.8 & $34.8-46.7$ & 34.0 & $28.2-39.7$ & 1.046 \\
Rio de Janeiro & 31.4 & $26.3-36.4$ & 23.3 & $18.6-27.9$ & 1.041 \\
Santos & 23.2 & $17.6-28.7$ & 20.4 & $15.0-25.6$ & 1.043 \\
Curitiba & 33.2 & $28.0-38.4$ & 23.9 & $19.2-28.6$ & 0.955 \\
Itajaí & 21.5 & $16.6-26.2$ & 12.5 & $8.6-16.3$ & 1.086 \\
\hline Total & 34.8 & $33.2-36.3$ & 27.7 & $26.2-29.1$ & - \\
\hline
\end{tabular}

*Weighted prevalence according to the size of the social network and the proportion of MSM in each city. 
and who they might invite to participate in this study". Moreover, as the analysis was conducted considering the 10 cities simultaneously, the sample was also weighted by the relative population size of Brazilian men, 18-64 years of age, in each site, and the proportional size of the MSM population in each municipality ${ }^{11}$ and considering each municipality as a stratum. This method of analyzing RDS dataset was proposed by Szwarcwald et al. ${ }^{12}$ and published studies applied this method ${ }^{13,14}$. The method proposed here considers both the chain-link effects and the unequal selection probabilities to estimate the prevalence rate, the standard error and 95\%CI, and the design effect. The 10-city dataset was then analyzed using logistic regression wherein each city was treated as a stratum.

Multivariate analysis involved: 1) a review of the literature to identify factors consistently identified in studies of discrimination due to sexual orientation; 2) bivariate analyses were conducted to identify additional variables for inclusion in the multivariate analysis. Adjusted odds ratio (OR) and 95\%CI were estimated to measure the association between selected factors and self-reporting of discrimination due to sexual orientation. Estimates with a $\mathrm{p}<0.10$ were selected for a weighted logistic regression analysis, which began with a saturated model and backward elimination that progressively removed variables until an adequate model of estimation was selected. Data was analyzed using Stata ${ }^{\circledR}$, version 12 (Stata Corp, College Station, Texas, USA).

\section{RESULTS}

A sample of 4,048 MSM were initially recruited in 10 Brazilian cities - 188 (4.46\%) were considered ineligible and one refused to participate -, for a total of 3,859 participants. Of these, 3,635 MSM (94.2\%) provided an answer to the discrimination question and were included in this analysis.

The overall prevalence of self-reported discrimination was $27.7 \%$ (95\%CI 26.2-29.1), ranging from $21.5 \%$ in Itajaí to $47 \%$ in Manaus (Table 1). Location of the discrimination included the street environment (13.7\%), shopping areas (6.9\%), entertainment locations (6.4\%), school or university (5.9\%), religious gatherings (3.7\%), and in health services (1.3\%). Participants were mostly young (60.5\%), had a level of education of 8-14 years (57.4\%), self-identified as pardo (53.8\%), were single (84.4\%), and living on a monthly income (47.6\%) of less than one Brazilian minimum wage (R\$465 = US\$230 in 2009). They identified themselves as gay or homosexual (50.5\%), bisexual (30.3\%), MSM (11.4\%), and heterosexual (7.7\%). Almost a third (27.2\%) reported unprotected receptive anal intercourse (URAI) with casual male partners in the last six months and almost half (47.5\%) reported URAI with steady male partner in the last six months. More than half reported consistent condom use with casual male partners during the past year (72.8\%), while $52.5 \%$ reported condom use with steady partners. Half of the participants reported having been subjected to some kind of violence: sexual (14.6\%), verbally threatened or humiliated (42.3\%), or physical violence (15.9\%). Few received STD counseling in health settings (11.8\%). Feeling sad or depressed during the last six months and having suicidal thoughts during the last six months was reported by $14.6 \%$ and $19.7 \%$, respectively. The majority reported low or moderate consumption of alcoholic beverages (36.1\% and $49.5 \%$ respectively). And few (9.9\%) reported community involvement and support (Table 2).

In bivariate analysis, the following factors were identified with the self-reporting of discrimination due to sexual orientation: age less than or equal to 30 years, $8-14$ and $\geq 15$ years of education, identifying as gay or homosexual, bisexual or MSM, URAI with casual male partners in the last six months, URAI with steady male partner in the last six months, not having received counseling for STD in health settings, feeling sad or depressed during the last six months, suicidal thoughts during the last six months, and reported community involvement and support (Table 3). 
Table 2. Distribution of characteristics of the 3,635 MSM (men who have sex with men) participants of the study in 10 Brazilian cities.

\begin{tabular}{|c|c|c|}
\hline Characteristic & $\mathrm{n}^{\mathrm{a}}$ & $\%$ Weighted $^{b}$ \\
\hline \multicolumn{3}{|c|}{ Self-reported discrimination in the last 12 months } \\
\hline Yes & 1,266 & 27.7 \\
\hline No & 2,369 & 72.3 \\
\hline \multicolumn{3}{|l|}{ Age } \\
\hline$\leq 30$ years & 2,602 & 60.5 \\
\hline$>30$ years & 1,033 & 39.5 \\
\hline \multicolumn{3}{|l|}{ Years of education } \\
\hline 0-7 years & 727 & 28.4 \\
\hline $8-14$ years & 2,338 & 57.4 \\
\hline$\geq 15$ years & 570 & 14.2 \\
\hline \multicolumn{3}{|l|}{ Skin color/ethnicity } \\
\hline White & 1,011 & 26.2 \\
\hline Black & 458 & 12.6 \\
\hline Pardo (Brown) & 2,047 & 53.84 \\
\hline Yellow/Indigenous & 119 & 3.0 \\
\hline \multicolumn{3}{|l|}{ Conjugal situation } \\
\hline Married or lives with companion & 592 & 16.3 \\
\hline Single/Widowed/Divorced/Separated & 3,043 & 83.7 \\
\hline \multicolumn{3}{|l|}{ Monthly income } \\
\hline$\leq 1$ minimum wage & 1,666 & 47.6 \\
\hline$\geq 2$ minimum wage & 1,969 & 52.4 \\
\hline \multicolumn{3}{|l|}{ Sexual orientation } \\
\hline Heterosexual & 281 & 7.7 \\
\hline Gay/Homosexual & 1,836 & 50.5 \\
\hline Bisexual & 1,103 & 30.3 \\
\hline MSM & 415 & 11.4 \\
\hline \multicolumn{3}{|c|}{ URAI with casual male partners in the last 6 months } \\
\hline Yes & 567 & 27.2 \\
\hline No & 1,597 & 72.8 \\
\hline \multicolumn{3}{|c|}{ URAI with steady male partners in the last 6 months } \\
\hline Yes & 828 & 47.5 \\
\hline No & 884 & 52.5 \\
\hline \multicolumn{3}{|l|}{ Counseling about STD in health service } \\
\hline Yes & 595 & 11.8 \\
\hline No & 3,040 & 88.2 \\
\hline \multicolumn{3}{|l|}{ Verbal violence } \\
\hline Yes & 1,652 & 42.3 \\
\hline No & 1,983 & 57.7 \\
\hline \multicolumn{3}{|l|}{ Physical violence } \\
\hline Yes & 539 & 15.9 \\
\hline No & 3,096 & 84.1 \\
\hline \multicolumn{3}{|l|}{ Sexual violence } \\
\hline Yes & 576 & 14.6 \\
\hline No & 3,059 & 85.4 \\
\hline \multicolumn{3}{|l|}{ Felt sad or depressed in the last 6 months } \\
\hline No or infrequently & 3,159 & 80.3 \\
\hline Frequently & 475 & 19.7 \\
\hline \multicolumn{3}{|l|}{ Suicidal thoughts in the last 6 months } \\
\hline No or infrequently & 3,094 & 80.1 \\
\hline Frequently & 475 & 19.9 \\
\hline \multicolumn{3}{|l|}{ Use of alcohol } \\
\hline Low & 1,461 & 36.1 \\
\hline Moderate & 1,849 & 49.5 \\
\hline High & 323 & 14.4 \\
\hline \multicolumn{3}{|l|}{ Community involvement and support } \\
\hline Yes & 395 & 9.9 \\
\hline No & 3,240 & 90.1 \\
\hline
\end{tabular}

URAI: unprotected receptive anal intercourse; STD: sexuality transmitted diseases

axcluding missing data.

${ }^{\mathrm{b}}$ Weighting calculated according to the size of the social network and the proportion of MSM in each city. 
Table 3. Bivariate analysis of factors associated with the self-reporting of discrimination due to sexual orientation among men who have sex with men (MSM) in Brazil.

\begin{tabular}{|c|c|c|c|}
\hline Variable & wOR* & $95 \% \mathrm{Cl}$ & 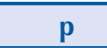 \\
\hline \multicolumn{4}{|l|}{ Age (years) } \\
\hline$\leq 30$ & 1.00 & & \\
\hline$>30$ & 1.84 & $1.59-2.17$ & $<0.001$ \\
\hline \multicolumn{4}{|l|}{ Years of education } \\
\hline $0-7$ years & 1.00 & & \\
\hline $8-14$ years & 2.68 & $2.21-3.25$ & $<0.001$ \\
\hline$\geq 15$ years & 2.86 & $2.23-3.67$ & $<0.001$ \\
\hline \multicolumn{4}{|l|}{ Skin color/ethnicity } \\
\hline White & 1.00 & & \\
\hline Black & 0.79 & $0.63-1.00$ & 0.06 \\
\hline Pardo (Brown) & 0.92 & $0.77-1.09$ & 0.3 \\
\hline Yellow/Indigenous & 0.75 & $0.48-1.20$ & 0.2 \\
\hline \multicolumn{4}{|l|}{ Conjugal situation } \\
\hline Married or lives with companion & 1.00 & & \\
\hline Single/Widowed/Divorced/Separated & 0.84 & $0.68-1.02$ & 0.09 \\
\hline \multicolumn{4}{|l|}{ Monthly income } \\
\hline$\leq 1$ minimum wage & 1.00 & & \\
\hline$\geq 2$ minimum wage & 0.93 & $0.80-1.08$ & 0.4 \\
\hline \multicolumn{4}{|l|}{ Sexual orientation } \\
\hline Heterosexual & 1.00 & & \\
\hline Gay/Homosexual & 14.70 & $9.02-23.97$ & $<0.001$ \\
\hline Bisexual & 3.82 & $2.30-6.34$ & $<0.001$ \\
\hline MSM & 3.39 & $1.99-5.76$ & $<0.001$ \\
\hline \multicolumn{4}{|c|}{ URAI with casual male partners in the last 6 months } \\
\hline No & 1.00 & & \\
\hline Yes & 1.38 & $1.12-1.70$ & $<0.001$ \\
\hline \multicolumn{4}{|c|}{ URAI with steady male partners in the last 6 months } \\
\hline No & 1.00 & & \\
\hline Yes & 1.97 & $1.58-2.45$ & $<0.001$ \\
\hline \multicolumn{4}{|l|}{ Counseling about STD in health service } \\
\hline Yes & 1.00 & & \\
\hline No & 1.53 & $1.23-1.89$ & $<0.001$ \\
\hline \multicolumn{4}{|l|}{ Verbal violence } \\
\hline No & 1.00 & & \\
\hline Yes & 6.62 & $5.62-7.80$ & $<0.001$ \\
\hline \multicolumn{4}{|l|}{ Physical violence } \\
\hline No & 1.00 & & \\
\hline Yes & 3.98 & $3.26-4.86$ & $<0.001$ \\
\hline \multicolumn{4}{|l|}{ Sexual violence } \\
\hline No & 1.00 & & \\
\hline Yes & 2.96 & $2.45-3.58$ & $<0.001$ \\
\hline \multicolumn{4}{|l|}{ Felt sad or depressed in the last 6 months } \\
\hline No or infrequently & 1.00 & & \\
\hline Frequently & 1.47 & $1.23-1.75$ & $<0.001$ \\
\hline \multicolumn{4}{|l|}{ Suicidal thoughts in the last 6 months } \\
\hline No or infrequently & 1.00 & & \\
\hline Frequently & 1.48 & $1.24-1.76$ & $<0.001$ \\
\hline \multicolumn{4}{|l|}{ Use of alcohol } \\
\hline Low & 1.00 & & \\
\hline Moderate & 0.94 & $0.81-1.10$ & 0.5 \\
\hline High & 0.58 & $0.45-0.74$ & $<0.001$ \\
\hline \multicolumn{4}{|l|}{ Community involvement and support } \\
\hline No & 1.00 & & \\
\hline Yes & 2.73 & $2.19-3.41$ & $<0.001$ \\
\hline
\end{tabular}

URAI: unprotected receptive anal intercourse; STD: sexuality transmitted diseases

* Weighted odds ratio calculated according to the size of the social network and the proportion of MSM in each city. 
Table 4. Analysis by logistic regression of factors associated with self-reporting of discrimination due to sexual orientation amongst men who have sex with men (MSM) in Brazil.

\begin{tabular}{|c|c|c|}
\hline Variable & wOR $(95 \% \mathrm{Cl}) *$ & $\mathbf{p}$ \\
\hline \multicolumn{3}{|l|}{ Age (years) } \\
\hline$\leq 30$ & 1.00 & \\
\hline$>30$ & $2.45(1.88-3.20)$ & $<0.001$ \\
\hline \multicolumn{3}{|l|}{ Years of education } \\
\hline $0-7$ years & 1.00 & \\
\hline $8-14$ years & $2.02(1.41-2.88)$ & $<0.001$ \\
\hline$\geq 15$ years & $1.80(1.19-2.72)$ & 0.005 \\
\hline \multicolumn{3}{|c|}{ URAI with steady male partners in the last 6 months } \\
\hline No & 1.00 & \\
\hline Yes & $1.89(1.50-2.39)$ & $<0.001$ \\
\hline \multicolumn{3}{|l|}{ Physical violence } \\
\hline No & 1.00 & \\
\hline Yes & $2.97(2.15-4.10)$ & $<0.001$ \\
\hline \multicolumn{3}{|l|}{ Sexual violence } \\
\hline No & 1.00 & \\
\hline Yes & $2.21(1.63-3.00)$ & $<0.001$ \\
\hline \multicolumn{3}{|c|}{ Suicidal thoughts in the last 6 months } \\
\hline No or infrequently & 1.00 & \\
\hline Frequently & $1.42(1.04-1.94)$ & 0.02 \\
\hline \multicolumn{3}{|c|}{ Community involvement and support } \\
\hline No & 1.00 & \\
\hline Yes & $1.70(1.21-2.40)$ & $<0.001$ \\
\hline
\end{tabular}

In the final weighted multivariate logistic model (Table 3), MSM who were 30 years of age or younger had over two times greater odds of self-reporting discrimination than older subjects ( $\mathrm{OR}=2.45,95 \% \mathrm{CI} 1.88-3.20)$. MSM with higher levels of education - eight to 14 years $(\mathrm{OR}=2.02,95 \% \mathrm{CI} 1.41-2.88)$ or more than 15 years $(\mathrm{OR}=1.80,95 \% \mathrm{CI} 1.19-2.27)$, had a greater chance of self-reporting discrimination due to sexual orientation compared with those with less than seven years of education.

The odds of self-reporting discrimination due to sexual orientation was greater among MSM who reported experience of physical violence $(\mathrm{OR}=2.97,95 \% \mathrm{CI} 2.154-4.10)$, sexual violence (OR $=2.21,95 \%$ CI 1.63-3.00), had frequently suicidal thoughts over the last six months $(\mathrm{OR}=1.42,95 \% \mathrm{CI} 1.04-1.94)$, or had reported community involvement and support (OR $=1.70$, 95\%CI 1.21-2.40) than among those that did not report these experiences. Furthermore, MSM who reported URAI with steady male partners in the last six months had a greater chance of self-reporting discrimination due to sexual orientation than those that reported consistent condom use (OR $=1.89,95 \%$ CI 1.50-2.39) (Table 4).

\section{DISCUSSION}

Prevalence of self-reporting discrimination due to sexual orientation was as high in this study as encountered in countries where homosexuality is criminalized, such as Namibia, Botswana, and Malawi, countries that report levels of discrimination of $24.7 \%, 27.4 \%$, and $19.1 \%$, respectively ${ }^{15}$. The prevalence encountered in our study was similar to or greater than that reported in many cities in the United States of America. In Phoenix, Albuquerque, and Austin, $11.2 \%$ of young gay and bisexual men from those three cites reported experiencing of discrimination ${ }^{16}$. In San Francisco, 30.1\% reported one or more experiences of discrimination because of sexual orientation: $9.6 \%$ were assaulted, $4.1 \%$ were discriminated against 
professionally, and $16.4 \%$ had been discriminated against personally ${ }^{17}$. In New York and Los Angeles, a study undertaken with Latino MSM estimated a rate of homophobia in the last 12 months of $17 \%$ and $14 \%$, respectively ${ }^{18}$.

In our study, the youngest subjects reported a greater prevalence of discrimination due to sexual orientation than older MSM. This is similar to findings such as the study cited above in the USA, where the chance of suffering verbal abuse and physical violence was greater among MSM younger than 21 years of age, in comparison to older MSM ${ }^{16}$. Another study in five countries showed that younger MSM had a greater perception of discrimination and internalized homophobia, in comparison with older MSM, and had less access to HIV preventive services ${ }^{19}$. Several factors may account for this phenomena: discrimination may be voiced more frequently by younger heteronormative populations, younger populations of MSM may be more open about their identities or more willing to see microaggressions as discrimination, or psychological compensation may be occurring in older MSM: repeated exposure to abuse in early phases of life may result in psychological desensitization and in the creation of cognitive mechanisms that help support or neutralize the effects of abuse ${ }^{20}$.

Recently in Brazilian society, new forms of gay sociability are being seen including interaction through the internet and "apps" ${ }^{21}$, as well as more open relationships between younger gays and their families. New studies are required to better understand the effects of these changes in the field of health, as well as exploring responses to prejudice and discrimination that improve health of the entire population.

Discrimination can significantly affect the mental health of gays and other MSM ${ }^{16,17,22}$. Our results show that MSM who frequently experienced suicidal thoughts had greater odds of self-reporting discrimination due to sexual orientation. In a study undertaken in the USA, people with experiences of discrimination and physical violence were two times as likely to have suicidal thoughts ${ }^{16}$ when compared to those who had not suffered these experiences. In a study in Tanzania, MSM who suffered moral and verbal abuse showed the highest levels of depression ${ }^{22}$. In another study using the 2009 RDS dataset, MSM who experienced sexual violence, independently of the effect of other variables, had a two times greater odds of reporting suicidal thoughts than those not reporting ${ }^{14}$. A study carried out in Lesotho showed that depression was positively associated with: feeling of rejection by friends because of sexual orientation, being verbally discriminated because of homosexuality, fear to walk in public places, and history of blackmail ${ }^{23}$.

Our study showed that MSM that reported URAI with steady male partners had a greater chance of self-reporting discrimination due to sexual orientation, when compared with those who always used condoms. Other studies indicate that the experience of discrimination can increase the chance of exposure to riskier sexual behaviors, such as unprotected anal $\operatorname{sex}^{17,18,24-26}$. In another study using RDS conducted in 2009, various factors were independently associated with unprotected anal sex: living with a male partner, illicit drug use, having a stable partnership, having sex with men only, having few friends encouraging condom use, and high self-perceived risk for HIV infection ${ }^{13}$.

The literature has also indicated that the effects of stigma and discrimination can be an important barrier for MSM to access health services ${ }^{4}$, diminishing the possibility for HIV testing ${ }^{27}$. It is important to emphasize that after more than three decades of the HIV/AIDS epidemic, fear of going to an HIV/AIDS reference center and being recognized by others as HIV positive is still reported ${ }^{5,28}$. Furthermore, we still encounter in the literature reports that HIV infection among MSM is justified as an example of "deserving it", a type of punishment due to immoral behavior ${ }^{28}$. Other negative images that can act as barriers to health care services access by MSM is the idea of homosexuals as "social deviants, or adepts of dangerous and reprehensible practices"21. Regarding these social markers or values associated with homosexual practices, Silva ${ }^{29}$ calls attention to how unprotected sexual practices is interpreted differently: while heterosexuals report unprotected sex as "only" a search for greater sexual pleasure, they interpret unprotected sex among MSM as a risk taking behavior. 
On one hand, heterosexuality is considered to be within normality and, on the other hand, homosexuality happens on the margins, understood as "strange", "stupid" or "pathological"

In our study, the chance of reporting discrimination due to sexual orientation was greater among MSM who did not receive counseling for STD in health care settings. We cannot establish a causal relationship of these factors, but we can hypothesize that such self-reporting can be a maker of potential discrimination in health services in Brazil ${ }^{30}$.

In terms of limitations, interpretation of RDS data remains controversial, but it does improve on snowball sampling by generating longer chains, and can be operationally systematic and rigorous. Here, when used to generate a national-level sample, a further limitation is that that "RDS samples are not designed to be merged, and are best analyzed on a site by site basis. Aggregating the independent networks to generate a single sample violates an assumption of RDS that a sample forms one complete network component. A related limitation is that the 10 cities selected may not represent MSM in Brazil. The cross-sectional design does not permit the identification of a temporal association between exposure and outcome; therefore, we do not know if the self-reporting of discrimination owing to sexual orientation is a result of the analyzed variable or if these are a consequence of the discrimination. Results of RDS studies should avoid extrapolations to other settings.

In terms of strengths, in our study, whereas other sampling methods were without sampling frames, RDS was one of the methods available to assess hard-to-reach groups, which may bring concrete gains, as was shown in a comparison of RDS and other sampling methods ${ }^{31}$.

It is important to remember that, while Brazil does not possess laws that criminalize homosexuality, Brazilian culture is marked by machismo (male chauvinism) and patriarchalism ${ }^{6}$, which, in many situations, exposes MSM to stigma, discrimination, and violence. In our study, we observed that physical and sexual violence were associated with self-reporting of discrimination due to sexual orientation, indicating that the experiences of violence can be understood by MSM as outcomes consequent to discrimination. Sabidó et al. ${ }^{14}$ also found similar results between sexual violence and self-reporting of discrimination.

Our study also shows that MSM who reported community involvement and support had a greater likelihood of self-reporting discrimination. A previous study, undertaken with 406 MSM who reported community involvement and support showed that MSM who self-report discrimination had a $50 \%$ higher chance of participating in these group ${ }^{32}$. It is likely that membership either exposes MSM to discrimination or enhances MSM willingness to report discrimination.

Although Lesbians, Gays, Bisexuals and Transgender social movements in Brazil are long-lasting and well-established, Brazil has still not developed legal mechanisms to respond to discrimination against sexual minority populations. Furthermore, current religious, political, and social movements in Brazil appear to be moving in an opposite direction, leading to a still greater increase in discrimination and stigma (such as the recent prohibition of educational videos and material regarding comprehensive sexual education in Brazilian schools ${ }^{33}$ ). Concerns for MSM health, including HIV/AIDS mandate re-mobilizing government and civil society to both restore the status quo ante, and to more broadly defend human rights for the social and physical protection of minority populations. To not do so diminishes the health of us all.

\section{REFERENCES}

1. Beyrer C, Baral SD, Griensven F, Goodreau SM. Chariyalertsak S, Wirtz AL, et al. Global epidemiology of HIV infection in men who have sex with men. Lancet. 2012;380(9839):367-77. https://doi.org/10.1016/S0140-6736(12)60821-6 
2. Kerr LRFS, Mota RS, Kendall C, Pinho AA, Melo MB, Guimarães MDC, et al. HIV among MSM in a large middle-income country. AIDS. 2013;27(3):427-35. https://doi.org/10.1097/QAD.0b013e32835ad504

3. Beyrer C, Wirtz AL, Walker D, Johns B, Sifakis F, Baral SD. The global HIV epidemics among men who have sex with men. Washington (DC): The World Bank; 2011 [cited 2017 Jul 31]. Available from: http://siteresources.worldbank.org/INTHIVAIDS/Resources/375798-1103037153392/ MSMReport.pdf

4. Baral SD, Grosso A, Holland C, Papworth E. The epidemiology of HIV among men who have sex with men in countries with generalized HIV epidemics. Curr Opin HIV AIDS. 2014;9(2):156-67. https://doi.org/10.1097/COH.0000000000000037

5. Hoffmann M, MacCarthy S, Batson A, Crawford-Roberts A, Rasanathan J, Nunn A, et al. Barriers along the care cascade of HIV-infected men in a large urban center of Brazil. AIDS Care. 2016;28(1):5762. https://doi.org/10.1080/09540121.2015.1062462

6. Itaborahy LP, Zhu J. State-sponsored homophobia: a world survey of laws: criminalisation, protection and recognition of same-sex love. 8.ed. Geneva: ILGA; c2013 [cited 2017 Jul 31]. p.41-109. Available from: http://old.ilga.org/Statehomophobia/ILGA_State_Sponsored_Homophobia_2013.pdf

7. Parker RG. Behaviour in Latin American men: implications for HIV/AIDS interventions. Int I STD AIDS. 1996;7 Suppl 2:62-5. https://doi.org/10.1258/0956462961917663

8. Secretaria de Direitos Humanos (BR). Segundo relatório sobre violência homofóbica no Brasil: ano de 2012. Brasília (DF); 2012.

9. Heckathorn DD. Respondent-driven sampling: a new approach to the study of hidden populations. Soc Probl. 1997;44(2):174-99. https://doi.org/10.2307/3096941

10. Salganik MJ, Heckathorn DD. Sampling and estimation in hidden populations using respondent-driven sampling. Sociol Methodol. 2004;34(1):193-240. https://doi.org/10.1111/j.0081-1750.2004.00152.x

11. Ministério da Saúde (BR), Secretaria de Vigilância em Saúde, Departamento de DST, Aids e Hepatites Virais. Pesquisa de conhecimentos, atitudes e práticas na população brasileira. Brasília (DF); 2011. (Série G. Estatística e Informação em Saúde).

12. Szwarcwald CL, Souza Júnior PRB, Damacena GN, Barbosa Júnior A, Kendall C. Analysis of data collected by RDS among sex workers in 10 Brazilian cities, 2009: estimation of the prevalence of HIV, variance, and design effect. J Acquir Immune Defic Syndr. 2011;57:Suppl 3:S129-35. https://doi.org/10.1097/QAI.0b013e31821e9a36

13. Rocha GM, Kerr LRFS, Brito AM, Dourado I, Guimarães MDC. Unprotected receptive anal intercourse among men who have sex with men in Brazil. AIDS Behav. 2013;17(4):1288-95. https://doi.org/10.1007/s10461-012-0398-4

14. Sabidó M, Kerr LRFS, Mota RS, Benzaken AS, Pinho AA, Guimarães MDC, et al. Sexual violence against men who have sex with men in Brazil: a respondent-driven sampling survey. AIDS Behav. 2015;19(9):1630-41. https://doi.org/10.1007/s10461-015-1016-Z

15. Fay H, Baral SD, Trapence G, Motimed F, Umar E, lipinge S, et al. Stigma, health care access, and HIV knowledge among men who have sex with men in Malawi, Namibia, and Botswana. AIDS Behav. 2011;15(6):1088-97. https://doi.org/10.1007/s10461-010-9861-2

16. Huebner DM, Rebchook GM, Kegeles SM. Experiences of harassment, discrimination, and physical violence among young gay and bisexual men. Am J Public Health. 2004;94(7):1200-3. https://doi.org/10.2105/AJPH.94.7.1200

17. Hatzenbuehler ML, Nolen-Hoeksema S, Erickson SJ. Minority stress predictors of HIV risk behavior, substance use, and depressive symptoms: results from a prospective study of bereaved gay men. Health Psychol. 2008;27(4):455-62. https://doi.org/10.1037/0278-6133.27.4.455

18. Mizuno Y, Borkowf C, Millett GA., Bingham T, Ayala G, Stueve A. Homophobia and racism experienced by Latino men who have sex with men in the United States: correlates of exposure and associations with HIV risk behaviors. AIDS Behav. 2012;16(3):724-35. https://doi.org/10.1007/s10461-011-9967-1

19. Santos GM, Beck J, Wilson PA, Hebert P, Makofane K, Pyun T, et al. Homophobia as a barrier to HIV prevention service access for young men who have sex with men. I Acquir Immune Defic Syndr. 2013;63(5):e167-70. https://doi.org/10.1097/QAI.0b013e318294de80

20. Nuttbrock L, Hwahng S, Bockting W, Rosenblum A, Mason M, Macri M, et al. Psychiatric impact of gender-related abuse across the life course of male-to-female transgender persons. J Sex Res. 2010;47(1):12-23. https://doi.org/10.1080/00224490903062258 
21. Miskolci R. "Discreet and out of the gay scene" - notes on contemporary sexual visibility. Cad Pagu. 2015;(44):61-90. https://doi.org/10.1590/1809-4449201500440061

22. Anderson AM, Ross MW, Nyoni JE, McCurdy SA. High prevalence of stigma-related abuse among a sample of men who have sex with men in Tanzania: implications for HIV prevention. AIDS Care. 2015;27(1):63-70. https://doi.org/10.1080/09540121.2014.951597

23. Stahlman S, Grosso A, Ketende S, Sweitzer S, Mothopeng T, Taruberekera N, et al. Depression and social stigma among MSM in Lesotho: implications for HIV and sexually transmitted infection prevention. AIDS Behav. 2015;19(8):1460-9. https://doi.org/10.1007/s10461-015-1094-y

24. Aho J, Hakim A, Vuylsteke B, Semde G, Gbais HG, Diarrassouba M, et al. Exploring risk behaviors and vulnerability for HIV among men who have sex with men in Abidjan, Cote d'Ivoire: poor knowledge, homophobia and sexual violence. PLoS One. 2014;9(6):e99591. https://doi.org/10.1371/journal.pone.0099591

25. Ayala G, Bingham T, Kim J, Wheeler DP, Millett GA. Modeling the impact of social discrimination and financial hardship on the sexual risk of HIV among Latino and Black men who have sex with men. Am J Public Health. 2012;102 Suppl2:S242-9. https://doi.org/10.2105/AJPH.2011.300641

26. Buller AM, Devries KM, Howard LM, Bacchus LJ. Associations between intimate partner violence and health among men who have sex with men: a systematic review and meta-analysis. PLoS Med. 2014;11(3):e1001609. https://doi.org/10.1371/journal.pmed.1001609

27. Knox J, Sandfort T, Yi H, Reddy V, Maimane S. Social vulnerability and HIV testing among South African men who have sex with men. Int J STD AIDS. 2011;22(12):709-13. https://doi.org/10.1258/ijsa.2011.010350

28. Jeffries W 4th, Townsend ES, Gelaude DJ, Torrone EA, Gasiorowicz M, Bertolli J. HIV stigma experienced by young men who have sex with men (MSM) living with HIV infection. AIDS Educ. 2015;27(1):58-71. https://doi.org//10.1521/aeap.2015.27.1.58

29. Silva LAV. Pleasure without condom: new positionings on online interaction networks. Cad Pagu. 2010;(35):241-77. https://doi.org/10.1590/S0104-83332010000200009

30. Cerqueira-Santos E, Calvetti PU, Rocha KB, Moura A, Barbosa LH, Hermel J. Percepção de usuários gays, lésbicas, bissexuais e transgêneros, transexuais e travestis do Sistema Único de Saúde. Rev Interam Psicol. 2010 [cited 2017 Jul 31];44(2):235-45. Available from: http://www.academia.edu/23875748/Percep\%C3\%A7\%C3\%A3o_de_Usu\%C3\%A1rios_ Gays_L\%C3\%A9sbicas_Bissexuais_e_Transg\%C3\%AAneros_Transexuais_e_Travestis_do_ Sistema_\%C3\%9Anico_de_Sa\%C3\%BAde

31. Kendall C, Kerr LRFS, Gondim RC, Werneck GL, Macena RH, Pontes MK, et al. An empirical comparison of respondent-driven sampling, time location sampling, and snowball sampling for behavioral surveillance in men who have sex with men, Fortaleza, Brazil. AIDS Behav. 2008;12 Suppl 1:S97-104. https://doi.org/10.1007/s10461-008-9390-4

32. Guimarães MDC, Rocha GM, Pinho A, et al. Participação de homens que fazem sexo com homens em ONGs no Brasil. In: IX Congresso Brasileiro de Prevenção das DST e Aids; 28-31 ago 2012; São Paulo, Brasil.

33. Malta M, Beyrer C. The HIV epidemic and human rights violations in Brazil. J Int AIDS Soc. 2013;16(1):10-12. https://doi.org/10.7448/IAS.16.1.18817

Funding: Ministry of Health/Secretariat of Health Surveillance/Department of IST, AIDS and Viral Hepatitis through the Project of International Technical Cooperation AD/BRA/03/H34 between the Brazilian Government and the United Nations Office on Drugs and Crime - UNODC.

Authors' Contribution: Study design and planning: ID, LRFSK, AMB, MDCG, AB, AAP, CK. Data collection, analysis and interpretation: LM, ID, SB, AMB, MDCG, AB, AAP, CK, LRFSK. Elaboration or revision of the manuscript: LM, ID, LAVS, SB, AMB, MDCG, AB, AAP, CK, LRFSK. Final version approval: LM, ID, MDCG. Public responsibility for the content of the article: $\mathrm{LM}$.

Conflict of Interest: The authors declare no conflict of interest. 